\title{
PENGARUH PEMBERIAN EKSTRAK SAMBILOTO (Andrographis Paniculata) TERHADAP GAMBARAN HISTOPATOLOGI GINJAL YANG DIINDUKSI GENTAMISIN PADA TIKUS (Rattus norvegicus)
}

\section{THE EFFECT OF LEAVES EXTRACT OF SAMBILOTO (Andrographis paniculata) ON RENAL HISTOPATHOLOGY FEATURES INDUCED BY GENTAMICIN IN WHITE RATS (Rattus norvegicus)}

\author{
Anggi Dwi Nugrahani 1), Lianny Nangoi 2), Dewa Ketut Meles 2), Thomas V. \\ Widiyatno 2), Iwan Sahrial Hamid 2), Kuncoro Puguh Santoso 2) \\ 1) Mahasiswa, 2) Dosen \\ Fakultas Kedokteran Hewan Universitas Airlangga \\ Kampus C UNAIR, Jl. Mulyorejo-Surabaya 60115 \\ Telp. 031-5992785, Fax. 031-5993015 \\ Email: jbmvunair@gmail.com
}

\begin{abstract}
This research was aimed to know the effect of leaves extract of sambiloto as a nephroprotector on renal histopathology features induced by gentamicin in white rats (Rattus norvegicus). The effect of leaves extract of sambiloto was tested in 25 rats. Twenty five male white rat were randomly divided into five groups; K- as negative control was given carboxy methyl cellulosa in 15 days, P0 was given carboxyl methyl cellulosa in 15 days, P1 was given leaves extract of sambiloto of $177 \mathrm{mg} / \mathrm{kg}$ bw/day/po in 15 days, P2 was given leaves extract of sambiloto of $189 \mathrm{mg} / \mathrm{kg}$ bw/day/po in 15 days, P3 was given leaves extract of sambiloto of 239,5 $\mathrm{mg} / \mathrm{kg} \mathrm{bw} /$ day/po in 15 days. On the 15 day of experimental, P0, P1, P2, P3 was given 200 $\mathrm{mg} / \mathrm{kg}$ bw of gentamicin. Gentamicin solutions on P0, P1, P2 and P3 treated through intramuscular injection. After 24 hours of gentamicin induced, take the rats renal by laparotomy and then making preparations histopathology with staining Haematoxylin-Eosin (HE). Based on the result of Kruskall-Wallis statistical analysis on renal histopathology showed this research that the treatment have significant difference $(\mathrm{p}<0,05)$. The leaves extract of sambiloto treated group (P3) gave the best value on the renal morfology, it gave a good effects in preventing nephrotoxicity in white rats.
\end{abstract}

Key words: Sambiloto extract, gentamicin-induced, nephrotoxicity, acute renal failure (ARF), renal histopathology.

\section{PENDAHULUAN}

Ginjal merupakan organ utama dalam perkemihan dan berhubungan dengan struktur lainnya untuk memfasilitasi pengeluaran urin. Fungsi dari sistem perkemihan sebagian besar dijalankan oleh sepasang organ ginjal (Hestianah dkk., 2014). Apabila terjadi kerusakan ginjal akan menyebabkan berkurangnya fungsi ginjal (Winearls, et al., 2016).

Nefrotoksisitas adalah salah satu masalah ginjal yang paling umum dan terjadi di saat tubuh terkena obat kimia atau toksin (Lakshmi, et al., 2012).
Oleh karena itu perlu dilakukan tindakan pencegahan dan terapi dalam menangani nefrotoksisitas. Andrographis paniculata adalah tanaman yang memiliki banyak kandungan seperti diterpen, lakton Kandungan ekstrak daun dari beberapa tanaman tradisional memiliki potensi yang baik digunakan dalam kerusakan ginjal (Lakshmi, et al., 2012). Terdapat banyak faktor yang dapat menimbulkan nefrotoksisitas, salah satunya penggunaan obat gentamisin.

Penelitian ini bertujuan untuk mengetahui pengaruh penggunaan 
ekstrak daun sambiloto (Andrographis paniculata) dalam mengurangi tingkat kerusakan sel tubulus ginjal pada hewan coba yang diinduksi gentamisin dosis toksik.

\section{METODE PENELITIAN}

\section{TEMPAT DAN WAKTU PENELITIAN}

Pemeliharaan tikus di Kandang Hewan Coba Fakultas Kedokteran Hewan Universitas Airlangga. Pembuatan ekstrak bahan sediaan di Laboratorium Farmakologi Fakultas Kedokteran Hewan Universitas Airlangga. Pemeriksaan Histopatologi Ginjal di Laboratorium Patologi Fakultas Kedokteran Hewan Universitas Airlangga. Penelitian ini dilakukan pada bulan Desember 2017 - Januari 2018.

\section{ALAT DAN BAHAN PENELITIAN}

Alat yang digunakan adalah sonde, botol air minum $250 \mathrm{ml}$, timbangan standar, pinset, gunting, scalpel, mortir, spuit $10 \mathrm{cc}$, spuit $1 \mathrm{cc}$, feeding tube ukuran 8, kapas, kertas perkamen, meja operasi, baki plastik, gunting operasi ujung tajam tumpul, gunting operasi tumpul-tumpul, mikroskop cahaya, gelas objek, gelas penutup dan kamera.

Bahan penelitian yang digunakan yaitu ekstrak daun sambiloto, gentamisin, aquades, CMC Na 0,5\%, ether, organ ginjal.

\section{PROSEDUR PENELITIAN}

Serbuk daun sambiloto dilakukan maserasi, yaitu proses pengekstrakan simplisia dengan menggunakan pelarut etanol $96 \%$ dengan beberapa kali pengadukan pada temperatur kamar dan terlindung dari cahaya. Pada proses maserasi, sebanyak $1 \mathrm{~kg}$ serbuk kering simplisia diberi pelarut etanol sebanyak 3L ke dalam bejana maserasi, setelah itu ditutup dan dibiarkan selama 5 hari pada temperatur kamar dan terlindung dari cahaya sambil diaduk secara berkala. Ekstrak yang diperoleh dilakukan penyaringan yang dibantu dengan pompa vacuum, hasil dari maserasi tersebut diuapkan dengan alat rotatory evaporator pada suhu $50-55^{\circ} \mathrm{C}$ sehingga diperoleh hasil ekstrak kental.

Ekstrak daun sambiloto yang akan diberikan pada hewan coba disuspensikan dengan CMC Na 0,5\% di dalam mortir agar homogenitas larutan dapat dijaga. Pembuatan suspensi CMC $\mathrm{Na} 0,5 \%$ didapat dengan cara mencampur CMC Na 5 g dalam $100 \mathrm{ml}$ aquades.

Sebanyak 25 ekor tikus putih diadaptasi selama tujuh hari dan selama penelitian berlangsung diberi makan dan minum secara ad libitum, lalu dibagi menjadi lima kelompok, yaitu K-, P0, P1, P2, P3 yang setiap kelompok perlakuan terdiri dari lima ulangan. Kelompok Khanya diberi CMC Na 0,5\% sebanyak 1 $\mathrm{ml}$ selama 15 hari. Kelompok P1, P2, dan P3 merupakan kelompok yang diberi ekstrak daun sambiloto dalam berbagai dosis selama 15 hari, sedangkan P0 hanya diberi CMC Na 0,5\% selama 15 hari. Kemudian pada hari ke-15 perlakuan, kelompok P0, P1, P2 dan P3 diberi gentamisin dosis toksik. Pada hari ke-16 dilakukan pengambilan organ ginjal dengan melakukan laparotomi, sebelumnya hewan coba dianestesi dengan menggunakan ether. Organ ginjal diambil dalam keadaan jantung masih berdenyut. Ginjal dimasukkan ke dalam tabung plastik yang sebelumnya telah diisi buffer formalin 10\% sebagai fiksator. Selanjutnya ginjal diproses untuk pembuatan preparat histopatologi. Setelah itu, dilakukan pemeriksaan histopatologi ginjal menggunakan mikroskop dengan perbesaran 400x. 


\section{KELOMPOK PERLAKUAN}

$\mathrm{K}^{-} \quad$ : Kelompok tikus putih yang hanya diberi $\mathrm{CMC} \mathrm{Na} \quad 0,5 \%$ sebanyak $1 \mathrm{ml}$ tiap ekor tikus secara per oral selama 15 hari.

P0 : Kelompok tikus putih yang yang hanya diberi CMC Na 0,5\% sebanyak $1 \mathrm{ml}$ tiap ekor tikus secara per oral selama 15 hari.

P1 : Kelompok tikus putih yang diberi ekstrak daun sambiloto sebanyak $177 \mathrm{mg} / \mathrm{kg}$ BB tikus, yang dilarutkan dalam $\mathrm{CMC} \mathrm{Na}$ $0,5 \%$ secara per oral sebanyak 1 $\mathrm{ml}$ selama 15 hari.

P2 : Kelompok tikus putih yang diberi ekstrak daun sambiloto sebanyak $189 \mathrm{mg} / \mathrm{kg}$ BB tikus, yang dilarutkan dalam $\mathrm{CMC} \mathrm{Na}$ $0,5 \%$ secara per oral sebanyak 1 ml selama 15 hari.

P3 : Kelompok tikus putih yang diberi ekstrak daun sambiloto sebanyak 239,5 mg/kg BB tikus, yang dilarutkan dalam CMC Na $0,5 \%$ secara per oral sebanyak 1 $\mathrm{ml}$ selama 15 hari.

Pada hari ke-15 perlakuan, kelompok tikus P0, P1, P2, dan P3 diberi gentamisin dengan dosis $200 \mathrm{mg} / \mathrm{kg}$ berat badan secara intramuskuler (Pariat, et al., 1988).

\section{RANCANGAN PENELITIAN DAN ANALISIS DATA}

Rancangan penelitian yang digunakan yaitu Rancangan Acak Lengkap (RAL). Penentuan banyaknya sampel berdasarkan banyaknya perlakuan (t) dan ulangan (n). Ulangan pada penelitian ini menggunakan rumus menurut Federer (1955) sebagai berikut:

$$
\begin{aligned}
(\mathrm{t}-1)(\mathrm{n}-1) & \geq 15 \\
(5-1)(\mathrm{n}-1) & \geq 15 \\
4 \mathrm{n}-4 & \geq 15 \\
4 \mathrm{n} & \geq 19 \\
\mathrm{n} & \geq 5
\end{aligned}
$$
n : jumlah sampel pada masing- masing kelompok
t : jumlah perlakuan

Data yang diperoleh berdasarkan derajat kerusakan gambaran histopatologi ginjal diolah dengan penilaian peringkat (rank), selanjutnya dilakukan analisis statistik non parametrik dengan uji Kruskall-Wallis, karena data yang diperoleh berdasarkan skoring dan jika terdapat perbedaan yang nyata antar perlakuan $(p<0,05)$, maka dilanjutkan dengan uji MannWhitney (Mehotcheva, 2008).

\section{HASIL DAN PEMBAHASAN}

Berdasarkan perhitungan statistik yang telah didapat diketahui bahwa antara masing-masing perlakuan terdapat perbedaan yang nyata pada histopatologi sel tubulus ginjal tikus. Kelompok K- memiliki hasil yang berbeda nyata dengan P0, P1, P2, dan P3 $(\mathrm{p}<0,05)$.

Hasil pemeriksaan histopatologi ginjal tikus putih kelompok Kmenunjukkan sel tubulus ginjal normal (Gambar 1). Kelompok tikus putih P0 menunjukkan sel tubulus ginjal mengalami peningkatan nekrosis sel yang ditandai dengan adanya struktur sel yang mengalami kerusakan, adanya deskuamasi seluler dan terjadinya nekrosis sel yang ditandai dengan proses karyolisis (Gambar 2).

Kelompok tikus putih P1 menunjukkan sel tubulus hampir sama seperti kelompok P0, tetapi mulai menunjukkan penurunan tingkat nekrosis sel walaupun terlihat adanya degenerasi hidropik (Gambar 3)

Kelompok tikus putih P2 menunjukkan sel tubulus ginjal mengalami penurunan tingkat nekrosis sel walaupun masih ditemukan hemorhagi (Gambar 4). 
Kelompok tikus putih P3 hampir sama seperti kelompok P2 yaitu mengalami penurunan tingkat nekrosis sel tubulus ginjal, terlihat gambaran sel ginjal normal hampir mendekati kelompok K- (Gambar 5).

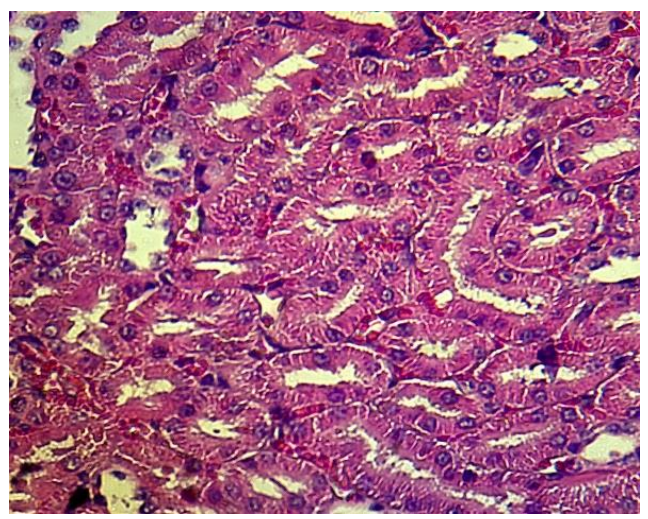

Gambar 1. Gambaran histopatologi ginjal tikus putih kelompok K- dengan perbesaran 400x menunjukkan sel tubulus ginjal normal.

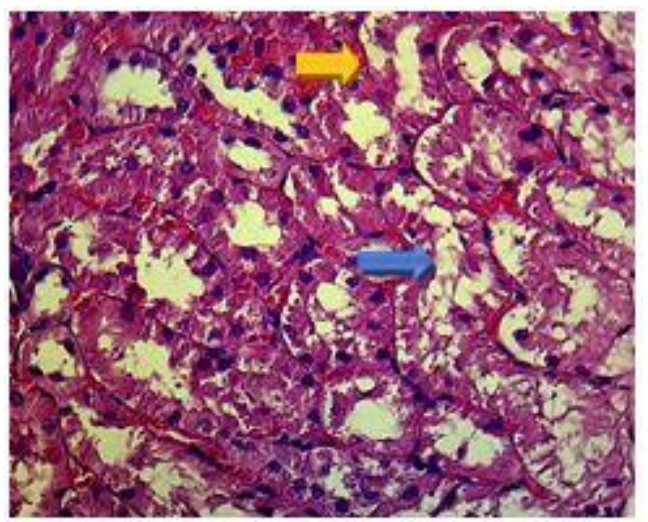

Gambar 2. Gambaran histopatologi ginjal tikus putih kelompok P0 dengan pemberian CMC Na 0,5\% + gentamisin menunjukkan adanya deskuamasi sel (panah kuning) dan sel nekrosis (panah biru).

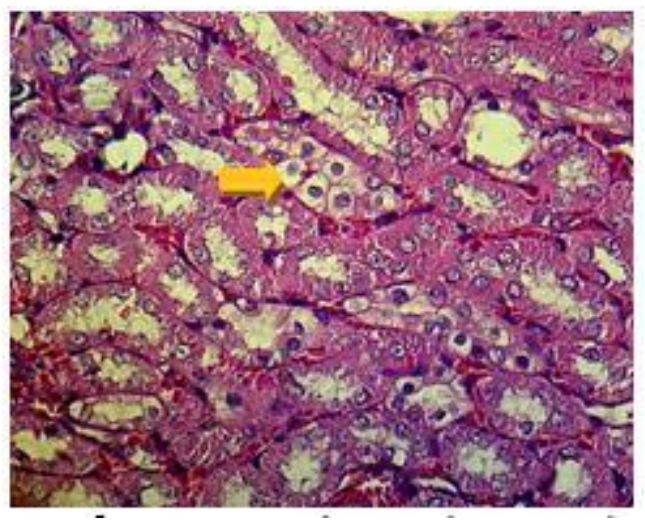

Gambar 3. Gambaran histopatologi ginjal tikus putih kelompok P1dengan pemberian ekstrak sambiloto $177 \mathrm{mg} / \mathrm{kg}$ BB tikus + gentamisin menunjukkan adanya degenerasi hidropik (panah kuning).

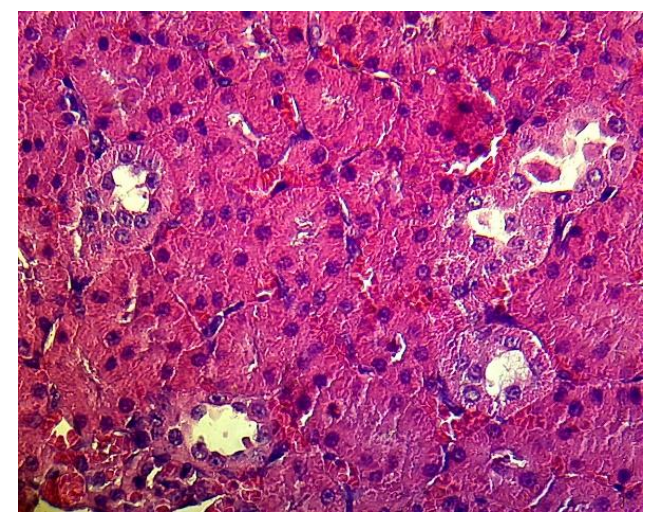

Gambar 4. Gambaran histopatologi ginjal tikus putih kelompok $\mathrm{P} 2$ dengan pemberian ekstrak sambiloto $189 \mathrm{mg} / \mathrm{kg}$ BB tikus + gentamisin terlihat adanya penurunan sel nekrosis.

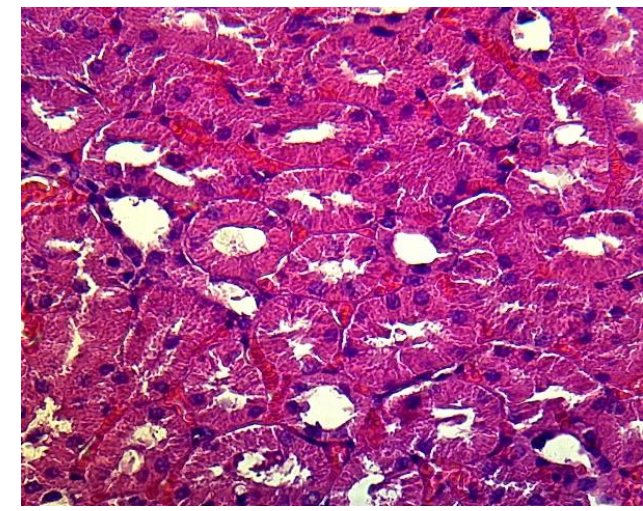

Gambar 5. Gambaran histopatologi ginjal tikus putih kelompok $\mathrm{P} 3$ dengan pemberian ekstrak sambiloto $239,5 \mathrm{mg} / \mathrm{kg}$ BB tikus + gentamisin mengalami penurunan sel nekrosis pada sel tubulus ginjal, terlihat gambaran sel ginjal normal hampir mendekati kelompok kontrol.

Pada penelitian ini membuktikan bahwa antar kelompok P1, P2, P3 dengan kelompok P0 terdapat perbedaan yang nyata $(\mathrm{p}<0,05)$. Hal ini menunjukkan bahwa kelompok yang diberi ekstrak daun sambiloto dosis 177 $\mathrm{mg} / \mathrm{kg}$ BB (P1); $189 \mathrm{mg} / \mathrm{kg}$ BB (P2); $239,5 \mathrm{mg} / \mathrm{kg}$ BB (P3) berpengaruh 
dalam penurunan tingkat nekrosis sel tubulus ginjal dibandingkan kelompok tanpa pemberian ekstrak daun sambiloto (P0).

Pemberian gentamisin cenderung menghasilkan radikal bebas yang menunjukkan kerusakan oksidatif pada tingkat sel korteks ginjal (Singh, et al., 2009). ROS adalah molekul yang tidak berpasangan dan oleh karena itu sangat tidak stabil dan sangat reaktif. Ketika terjadi peningkatan kadar ROS, tubuh akan merespon dengan memproduksi enzim SOD untuk menetralkan ROS (Widayati, 2018). Anion superoksida $(\mathrm{O} 2)$, radikal hidroksil bebas $(\mathrm{OH})$ dan oksida nitrat (NO) adalah radikal bebas yang penting dalam tubuh dan menghasilkan banyak radikal bebas lainnya terutama dari asam lemak tak jenuh, merupakan molekul yang tidak stabil dan agresif yang cenderung memberikan elektron tidak berpasangan ke molekul sel lain atau merebut elektron lain dari molekul lain untuk mencapai stabilitas (Singh, et al., 2009).

Oksida nitrat radikal bebas dapat membentuk RNS lain, seperti peroksinitrit, yang dibentuk oleh reaksi oksida nitrat dengan superoksida (Ratliff, et al., 2016). Dalam situasi patologis oksigen reaktif dan spesies nitrogen dihasilkan pada tingkat yang lebih tinggi dari normal. Selain mengandung konsentrasi tinggi asam lemak tak jenuh ganda, sel membran biologis dan organel sel menjadi sasaran dalam berbagai jenis kerusakan yang ditimbulkan. Mekanisme kerusakan biologis dan toksisitas spesies reaktif pada sistem biologis yang ditimbulkan antara lain stres oksidatif reversibel dan kerusakan oksidatif ireversibel. Stres oksidatif merupakan situasi ketidakseimbangan dengan oksidan yang meningkat atau penurunan antioksidan. (Repetto, et al., 2012).

Nitrit oksida dibentuk oleh berbagai isoform nitrit oksida sintase (NOS) untuk menghasilkan oksida nitrat. Oksida nitrat radikal bebas sangat selektif dalam sifat reaktifnya dan dapat terus membentuk RNS lain, termasuk peroksinitrit, yang dibentuk oleh reaksi oksida nitrat dengan superoksida (Ratliff, 2016). Peroksidasi lipid adalah reaksi berantai yang dimulai oleh abstraksi hidrogen atau penambahan radikal oksigen, menghasilkan kerusakan oksidatif dari asam lemak tak jenuh ganda (PUFA). Karena asam lemak tidak jenuh ganda lebih sensitif daripada yang jenuh, maka pengaktifan dari jembatan metilen ( $\mathrm{RH})$ merupakan lokasi target kritis dalam peran oksidan (Repetto, 2012). Reaksi RNS dengan asam lemak tak jenuh menghasilkan asam lemak teroksidasi dan nitrasi, yang memiliki berbagai tindakan biologis (Ratliff, et al., 2016).

Dengan adanya pemberian ekstrak sambiloto yang mampu bertindak sebagai antioksidan dapat memberi efek pada oksida yang terbentuk gentamisin, sehingga ikatan $\mathrm{NO}, \mathrm{NO}_{2}$, dan $\mathrm{NO}_{3}$ menjadi stabil. Efek penurunan sel nekrosis oleh ekstrak sambiloto ini dikarenakan adanya senyawa aktif yang terdapat dalam daun tanaman sambiloto, salah satu senyawa kimia yang berperan yaitu andrographolide. Andrographolide sebagai antioksidan mampu menghambat terbentuknya lipid peroksidase akibat adanya radikal bebas atau nekrosis (Wahyuni, 2005).

\section{KESIMPULAN}

Berdasarkan hasil penelitian dapat ditarik kesimpulan bahwa pemberian ekstrak daun sambiloto (Andrographis paniculata) mampu mencegah kerusakan sel tubulus ginjal yang diinduksi dengan gentamisin, dan dengan pemberian dosis $239,5 \mathrm{mg} / \mathrm{kg}$ BB ekstrak sambiloto mampu mencegah kerusakan ginjal akibat induksi gentamisin dosis toksik. 
DAFTAR PUSTAKA

Akbar, S. (2011). Andrographis paniculata: A Review of Pharmacological Activities and Clinical Effects. Alternative Medicine Review, 66-77.

Federer, Walter Theodore. (1955). Experimental Design, Theory And Application.

Hestianah, Eka Pramyrtha., Anwar, Chairul., Kuncorojakti, Suryo., Yustinasari, Lita Rakhma. (2014). Bahan Ajar Histologi Veteriner. In E. P. Hestianah, Bahan Ajar Histologi Veteriner (Jilid 2 ed., pp. 1-146). Surabaya: PT. Revka Petra Media.

Lakshmi, M. S., Reddy, U. K., \& Rani, S. R. K. S. (2012). A review on medicinal plants for nephroprotective activity. Asian J Pharm Clin Res, 5(4), 8-14.

Mehotcheva, T. H. (2008). The KruskalWallis Test. In Seminar in Methodology \& Statistics: http://www. let. rug. $\mathrm{nl} /$ nerbonne/teach/rema-statsmethseminar/presentations/Meh otcheva-2008-Kruskal-Wallis. pdf.

Pariat, C., Courtois, P., Cambar, J., Piriou, A., \& Bouquet, S. (1988). Circadian variations in the renal toxicity of gentamicin in rats. Toxicology letters, 40(2), 175-182.
Ratliff, B. B., Abdulmahdi, W., Pawar, R., \& Wolin, M. S. (2016). Oxidant mechanisms in renal injury and disease. Antioxidants $\mathcal{E}$ redox signaling, 25(3), 119-146.

Repetto, Marisa, Jimena Semprine, and Alberto Boveris. "Lipid peroxidation: chemical mechanism, biological implications and analytical determination." Lipid peroxidation. InTech, 2012.

Singh, P. P., Mahadi, F., Roy, A., \& Sharma, P. (2009). Reactive oxygen species, reactive nitrogen species and antioxidants in etiopathogenesis of diabetes mellitus type-2. Indian journal of clinical Biochemistry, 24(4), 324-342.

Wahyuni, Sri. (2005). Pengaruh Daun Sambiloto (Andrographis paniculata, nees) terhadap kadar SGPT dan SGOT Tikus Putih. Gamma, 45-53.

Winearls, C. (2016). Oxford Kidney Unit. , Chronic Kidney Disease Information for patients and their families (pp. 112). Oxford: Oxford University Hospitals NHS Foundation Trust. 